\title{
Aerodynamic Optimization of a Centrifugal Fan Using Response Surface Methodology
}

\author{
Tao Liu, Yingkun Zhang, Kunhang Li, Yu Wang, Jingyin Li ${ }^{*}$ \\ School of Energy and Power Engineering, Xi'an Jiaotong University, Xi'an, China \\ Email: `jyli@mail.xjtu.edu.cn
}

How to cite this paper: Liu, T., Zhang, Y.K., Li, K.H., Wang, Y. and Li, J.Y. (2019) Aerodynamic Optimization of a Centrifugal Fan Using Response Surface Methodology. Open Journal of Fluid Dynamics, 9, 92-105.

https://doi.org/10.4236/ojfd.2019.91007

Received: February 25, 2019

Accepted: March 25, 2019

Published: March 28, 2019

Copyright $\odot 2019$ by author(s) and Scientific Research Publishing Inc. This work is licensed under the Creative Commons Attribution International License (CC BY 4.0).

http://creativecommons.org/licenses/by/4.0/

\begin{abstract}
In this paper, the optimization scheme of a centrifugal fan under the constraints of the total pressure difference, efficiency and shaft power was carried out. The blade inlet angle $\beta_{1 A}$ and the blade outlet angle $\beta_{2 A}$ of the centrifugal impeller were optimized using the Response Surface Methodology (RSM). Nine optimization cases were presented. The aerodynamic performance and the flow field of the optimized model were carefully compared with the original model. The results show that the total pressure difference and the total-pressure efficiency increase by $5.7 \%$ and $4.2 \%$ respectively after the optimization. Compared with the original fan, the flow field inside the impeller of the optimized fan has been improved. The flow separation existing around the blade suction surface outlet is suppressed significantly. For fields in the volute, the optimization scheme has reduced the local vortex intensity and weakened the vortex scale. The flow field stability around the volute tongue is also correspondingly improved.
\end{abstract}

\section{Keywords}

Centrifugal Fan, Optimization, Response Surface Methodology

\section{Introduction}

Centrifugal fan, a widely used centrifugal machinery, plays an important role in industry. The centrifugal impeller is the key component of the centrifugal fan and it has a significant effect on the performance of the centrifugal fan. Lots of work on designing and optimizing the centrifugal impeller has been done over the past decades. The traditional engineering design method of the impeller was investigated by $\mathrm{Li}$ [1]. He studied the method to design some parameters of the impeller, including the meridian lines, blade number, blade inlet angle, blade outlet angle and so on. However, the traditional design method depends signifi- 
cantly on the engineering practice, which is a limit in meeting the diverse design objectives. Besides, the effects of some important design parameters on the aerodynamic performance of the centrifugal fan were investigated numerically, including the blade number [2], the blade loading [3] [4] and the meridional channel of the impeller [5].

With advances in numerical algorithms and computer hardware, the Computational Fluid Dynamics (CFD) has been widely used as a design tool. On the basis of CFD, several strategies have been applied for the optimization. Both genetic algorithms (GAs) [6] [7] and particle swarm optimization (PSO) methods [8] [9] are widely used. In addition, surrogate-based optimization (SBO) [5] [10] and Artificial Neural Network (ANN) [11] [12] become popular recently in the aerodynamic shape optimization of turbomachinery. But their requirement of the computational source is considerable.

Response surface method (RSM), as a global optimization method, is also widely used in the optimization procedure of turbomachinery. The method can utilize the information collected by different tools and perform tasks in parallel easily [13]. Guo et al. [14] studied a geometrical optimization for a mini-centrifugal compressor. The RSM was used in obtaining the first-order and the second-order regression models in the procedure. The results indicated a considerable improvement of the pressure ratio and the efficiency. Benim et al. [15] optimized an airfoil shape for small horizontal axis wind turbines by combining the CFD analysis with RSM and the Biobjective Mesh Adaptive Direct Search (BiMADS) algorithm. Their results demonstrated that the method used in the optimization of the blade shape was effective. In the research of Jang et al. [16], RSM was used to the shape optimization of a stator blade in a single-stage transonic axial compressor. Adiabatic efficiency was selected as an objective function of the skew angle at the mid-span section and the skew angle at the tip of the stator blade. After optimization, the adiabatic efficiency increased by $2.5 \%$ due to the suppression of the separation on the suction surface of the stator. Tang et al. [17] proposed a gradient-enhanced response surface model (GERSM), a new method used in the optimization of turbomachinery blades. The transonic NASA Rotor 67 blade row was optimized at the design speed near the peak efficiency using both the steepest decent optimization (SDO) and GERSM. The results showed that, compared with the traditional response surface, GERSM proved to be far more robust and accurate in the prediction of both the function value and the gradient. Kaibin et al. [18] presented an optimization strategy for a centrifugal impeller with the constraint on efficiency at the stall point. The impellers with different angular momentum distributions determined by RSM were generated and simulated. The optimal impeller was obtained, and the performance was improved greatly. The result indicated that RSM was effective in the optimization of the centrifugal impeller.

However, many studies mainly focused on the aerodynamic performance of the optimized model without the specific analysis of the flow field characteris- 
tics. In this paper, both the aerodynamic performance and the flow characteristics of the centrifugal fan were analyzed in detail, which is beneficial to understand which phenomena are to be either controlled or exploited to improve the aerodynamic performance. The paper is organized as follows. In Section 2, the main parameters of the original model are presented and the numerical approach is introduced. The optimization of the centrifugal impeller based on RSM is carried out in Section 3, and the nine cases under the optimization scheme are given. In Section 4, the optimization results are presented, and the flow characteristics of the impeller and fan are investigated in detail. The paper ends with conclusions in Section 5.

\section{Physical models and Numerical Approach}

\subsection{Parameters of the Original Model}

Table 1 shows the main parameters of the original fan. The total pressure difference of the fan is $1328 \mathrm{~Pa}$, and the shaft power is $6.1 \mathrm{~kW}$. Table 2 shows the main parameters of the original impeller designed by the traditional engineering design method. The impeller is designed with the rotating speed of $1450 \mathrm{r} \cdot \mathrm{min}^{-1}$ and has 15 back-bend blades. The shroud surface of the impeller is curved while the hub surface is a plane. The blade profile is designed in uniform deceleration method, which assures that the blade angle reduces in a constant ratio from blade outlet to inlet.

\subsection{Grid Generation and Boundary Conditions}

The volute and the collector are designed according to the engineering experience, which have a structured grid for the simulation. The hexahedral structured grid is applied in both the original impeller and the optimized impeller by using the software Turbo-Grid. The grid distribution of the fan is presented in Figure 1 . The validation of the grid was conducted for 5 cases, and the case with the total grid number of 7.8 million was adopted. In the adopted grid case, the grid number of the impeller is 2.5 million while the collector and the volute are 1.3 million and 4 million, respectively.

To analyze the flow field and the aerodynamic performance of the fan, a numerical investigation with the K- $\omega$ SST model in CFX was carried out. Inlet boundary condition, with the flow rate being set to $14,000 \mathrm{~m}^{3} \cdot \mathrm{min}^{-1}$, was given on the inlet of the collector. The outlet boundary condition was given on the volute outlet, and the outlet static pressure was set as $0 \mathrm{~Pa}$. The interfaces between the impeller and the stationary elements (collector and volute) were set as the frozen rotor. Numerical cases were regarded as convergent when the Root Mean Square (RMS) of residual is lower than $10^{-5}$.

\section{Response Surface-Based Optimization Scheme}

\subsection{Optimization Factors and Schemes}

Factor $\beta_{1 A}$ and $\beta_{2 A}$ represent the blade inlet angle and the outlet angle, which 
have great effects on the aerodynamic performance of the centrifugal fan. In this study, Central Composite Design (CCD), one method of RSM, was used due to its good performance in estimating the objective function. The CCD method requires central points and axial points to complete the design, each factor has five levels as shown in Table 3.

After identifying the factors and levels, a multi-objective optimization problem is formulated with three response variables: total pressure difference, shaft power and total-pressure efficiency. The design of experiment scheme in the CCD has 9 cases after removing the 4 same cases. All the nine cases in the optimization schemes as well as the CFX results of the total pressure difference, shaft power and total-pressure efficiency are listed in Table 4.
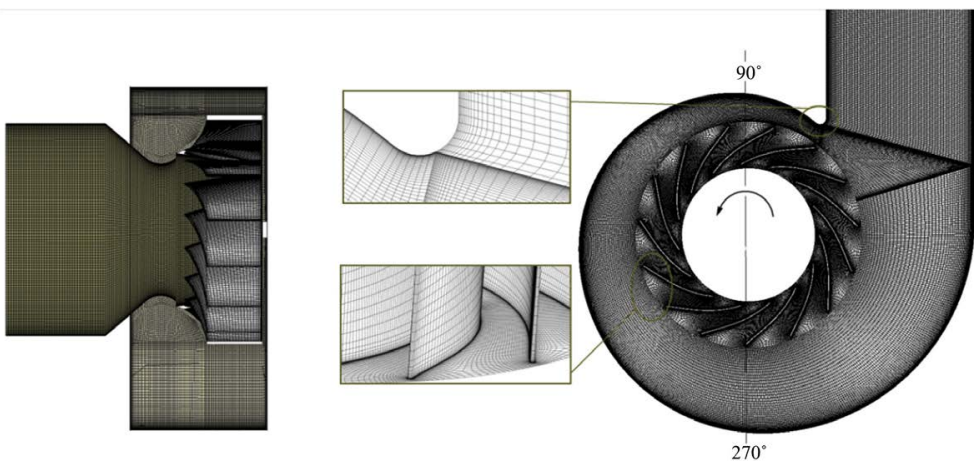

Figure 1. Grid distribution of the fan.

Table 1. Main parameters of the original fan.

\begin{tabular}{lcccccc}
\hline Variables & $\begin{array}{c}\text { Total } \\
\text { Pressure } \\
(\mathrm{Pa})\end{array}$ & $\begin{array}{c}\text { Shaft } \\
\text { Power } \\
(\mathrm{kW})\end{array}$ & $\begin{array}{c}\text { Total-Pressure } \\
\text { Efficiency } \\
(\%)\end{array}$ & $\begin{array}{c}\text { Flow } \\
\text { Rate } \\
\left(\mathrm{m}^{3} \cdot \mathrm{min}^{-1}\right)\end{array}$ & $\begin{array}{c}\text { Rotational } \\
\text { Speed } \\
\left(\mathrm{r} \cdot \mathrm{min}^{-1}\right)\end{array}$ & Media \\
\hline Values & 1328 & 6.1 & 84.0 & 14,000 & 1450 & air \\
\hline
\end{tabular}

Table 2. Main parameters of the original impeller.

\begin{tabular}{cc}
\hline Variables & Values \\
\hline Impeller outlet diameter $D_{2} / \mathrm{mm}$ & 700 \\
Impeller inlet diameter $D_{0} / \mathrm{mm}$ & 480 \\
Number of blades & 15 \\
Impeller outlet width $b_{2} / \mathrm{mm}$ & 175 \\
Impeller inlet width $b_{1} / \mathrm{mm}$ & 245 \\
Blade outlet angle $\beta_{2 A} /^{\circ}$ & 45 \\
Blade inlet angle $\beta_{1 A} /{ }^{\circ}$ & 25
\end{tabular}

Table 3. Factors and levels.

\begin{tabular}{cccccc}
\hline & \multicolumn{5}{c}{ Levels } \\
\cline { 2 - 6 } Factors & -1.414 & -1 & 0 & 1 & 1.414 \\
\hline$\beta_{1 A}{ }^{\circ}$ & 17.93 & 20 & 25 & 30 & 32.07 \\
$\beta_{2 A}{ }^{\circ}$ & 30.86 & 35 & 45 & 55 & 59.14 \\
\hline
\end{tabular}


Table 4. Schemes and numerical results of the design of experiment.

\begin{tabular}{cccccc}
\hline \multirow{2}{*}{ Schemes } & \multicolumn{5}{c}{ Numerical Results } \\
\cline { 2 - 6 } & $\beta_{1 A} /\left(^{\circ}\right)$ & $\beta_{2 A} /\left(^{\circ}\right)$ & $P_{\text {tot }} / \mathrm{Pa}$ & $N_{s} / \mathrm{kW}$ & $\eta_{\text {tot }} / \%$ \\
\hline 2 & 25 & 59.14 & 1543 & 6.7 & 89.6 \\
3 & 32.07 & 45 & 1420 & 6.4 & 86.1 \\
4 & 20 & 35 & 1478 & 6.3 & 91.4 \\
5 & 17.93 & 45 & 1632 & 6.8 & 93.3 \\
6 & 25 & 45 & 1458 & 6.3 & 89.8 \\
7 & 30 & 55 & 1534 & 6.9 & 86.9 \\
8 & 20 & 55 & 1624 & 6.9 & 91.6 \\
9 & 30 & 35 & 1360 & 5.9 & 89.5 \\
\hline
\end{tabular}

\subsection{The Sensitivity Analysis of the Impeller Parameters}

With the total pressure difference being targeted, the following second order fitting function was obtained from the RSM result:

$$
P_{t o t}=A-B \beta_{1 A}+C \beta_{2 A}+D \beta_{1 A} \beta_{2 A}+E \beta_{1 A}^{2}+F \beta_{2 A}^{2}
$$

here, $A, B, C, D, E$ and $F$ represent the constant number with the value of $2617.70,101.20,3.91,0.14,1.64$ and 0.001 respectively. The fitting function was obtained by using the Design-Expert, a useful software for RSM analysis. It is observed that the P-value of the fitting function is lower than 0.0001, which indicates the fitting function is significant.

With the Design-Expert, the sensitivity analysis for the total pressure difference of the given nine cases is presented in Figure 2. The figure indicates that the blade inlet angle $\beta_{1 A}$ and the blade outlet angle $\beta_{2 A}$ are sensitive for the total pressure difference of the impeller, and $\beta_{2 A}$ is more sensitive than $\beta_{1 A}$. As $\beta_{2 A}$ increases, the ability to generate energy of impeller will be enhanced. That is the reason why the total pressure difference behaves a positive correlation distribution. On the contrary, as $\beta_{1 A}$ increases, the total pressure difference curve shows a gradually decreasing trend. This phenomenon can be illustrated that the large blade inlet angle may cause the energy loss of the impact of the flow forces.

The second order fitting function for the shaft power can be expressed as:

$$
N_{s}=A-B \beta_{1 A}-C \beta_{2 A}+D \beta_{1 A} \beta_{2 A}+E \beta_{1 A}^{2}-F \beta_{2 A}^{2}
$$

here, $A, B, C, D, E$ and $F$ represent the constant number with the value of 11.6, $0.45,0.0085,3,0.00675$ and 0.0000625 respectively. The P-value of the fitting function is lower than 0.0001, which also indicates the fitting function is reliable.

In Figure 3, the sensitivity analysis for the shaft power of the given nine cases is presented. It can be seen that the blade inlet angle $\beta_{1 A}$ and the blade outlet angle $\beta_{2 A}$ are sensitive for the shaft power. As the curves presented, the shaft power 
decreases slowly and then increases slowly with the $\beta_{1 A}$ increasing. However, the shaft power has a positive correlation distribution trend as $\beta_{2 A}$ increases. It can be seen that for the shaft power, the influence of $\beta_{2 A}$ exceeds that of $\beta_{1 A}$. The second order fitting function for the total-pressure efficiency is shown as below:

$$
\eta_{\text {tot }}=A+B \beta_{1 A}+C \beta_{2 A}-D \beta_{1 A} \beta_{2 A}
$$

here, $A, B, C$ and $D$ represent the constant number with the value of $86.62,0.21$, 0.30 and 0.014 . It is found that the fitting function is significant because the $\mathrm{P}$-value of the fitting function is lower than 0.0001 .

Figure 4 shows the sensitivity analysis for the total-pressure efficiency of the given nine cases. As Figure 4 shows, both the blade inlet angle $\beta_{1 A}$ and the blade outlet angle $\beta_{2 A}$ have an important influence on the total-pressure efficiency. The total-pressure efficiency has a negative correlation distribution with the two factors increasing. Compared to the blade outlet angle $\beta_{2 A}$, the blade inlet angle $\beta_{1 A}$ has a greater impact on the total-pressure efficiency.

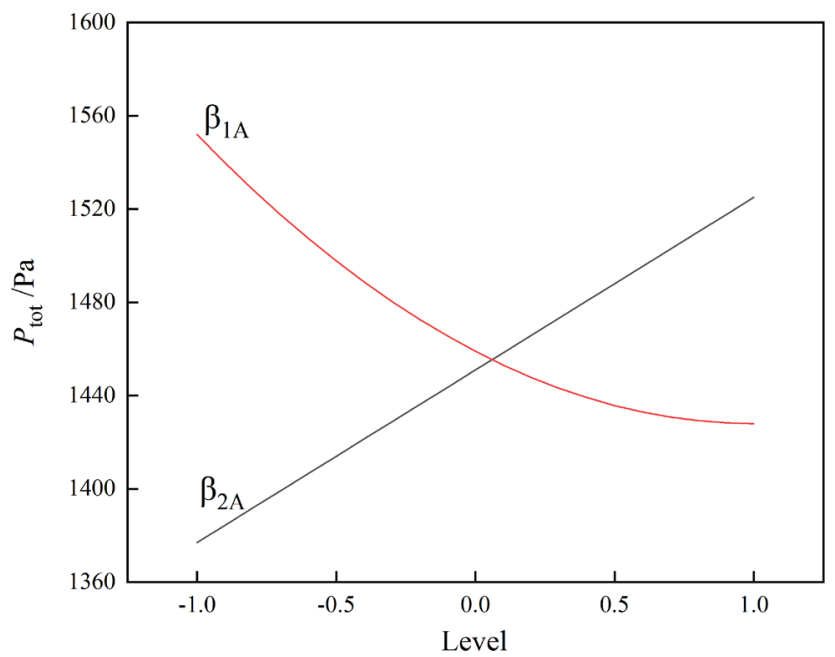

Figure 2. The sensitivity analysis of the total pressure difference.

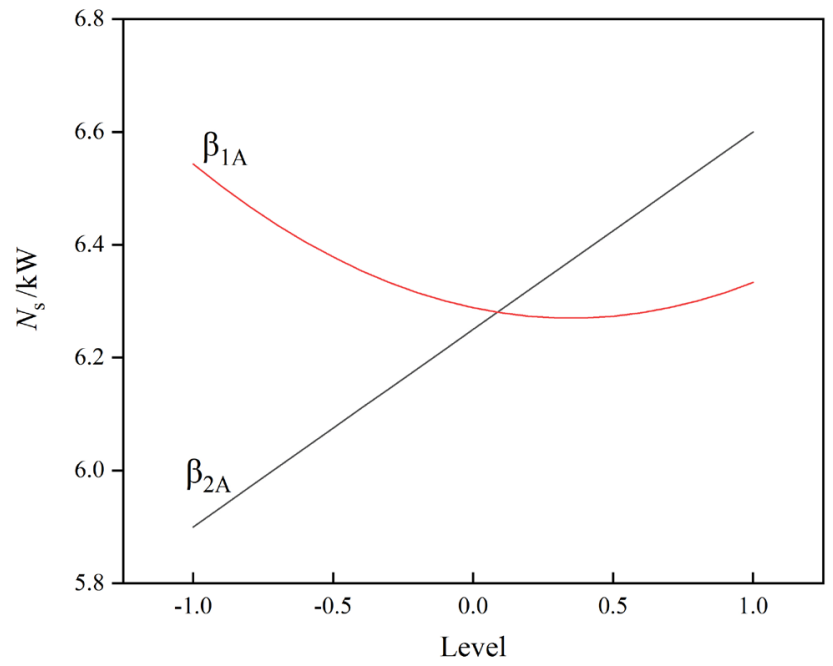

Figure 3. The sensitivity analysis of the shaft power. 


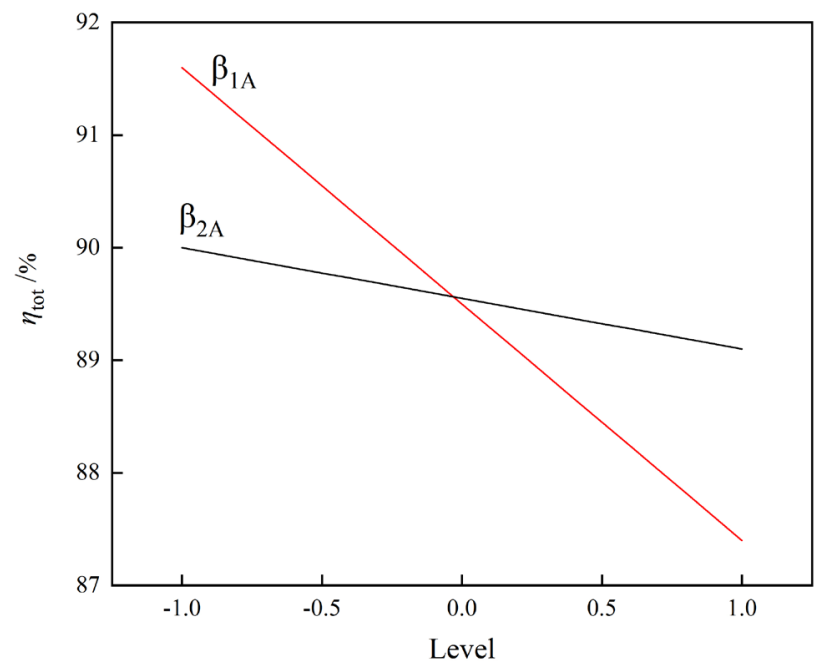

Figure 4. The sensitivity analysis of the total-pressure efficiency.

\section{Results and Discussion}

\subsection{Optimization Results}

The goal of optimization is to obtain the maximum values of the total pressure difference and the total-pressure efficiency. In addition, its shaft power needs to be less than $6.5 \mathrm{~kW}$. We obtained the optimal value of $\beta_{1 A}$ and $\beta_{2 A}$ from the fitting function. The values of them are $17.6^{\circ}$ and $42.5^{\circ}$ respectively. The optimized model was built and the optimization results were obtained by CFX. Table 5 shows the simulated results. It can be seen that the total pressure difference and the total-pressure efficiency increase by about by $6.4 \%$ and $4.6 \%$ respectively. Figure 5 shows the distribution of the total pressure difference and the total-pressure efficiency in the course of optimization. In the optimal point, the total-pressure efficiency is highest among design cases and the improvement of the impeller's performance is significant.

The fan with the optimized impeller is selected to be the optimized fan and simulated by CFX. The numerical results of it are presented in Table 6. The total pressure difference and the total-pressure efficiency increase by about $5.7 \%$ and $4.2 \%$ respectively. And the shaft power is less than the limit value $6.5 \mathrm{~kW}$. The aerodynamic performance of the fan is improved significantly, which indicates that the RSM used in the optimization procedure is effective.

\subsection{Analysis of the Impeller Internal Flow Condition}

The total pressure distributions at 50\% span of the impeller for both the original and optimized models are presented in Figure 6. Figure 6(a) shows that, the total pressure in the impeller increases radially and unevenly. A low pressure region caused by a large positive attack angle exists at the entrance of the suction surface, and a high energy region caused by the flow separation exists at the exit of the suction surface. Therefore, the dissipation of flow energy would be produced by the large positive attack angle and the flow separation in the original 
impeller. As shown in Figure 6(b), it can be seen that the total pressure in the impeller increases uniformly after optimization. The scales of both the low pressure region and the high energy region decrease significantly. It indicates that the impact of the flow forces on the impeller has been reduced and the flow separation has been suppressed effectively.

Figure 7 presents the relative velocity distribution in the impeller. Figure 7(a) and Figure 7(b) show that the velocity distributions in the impeller for both models are even near the hub. There is little difference between the original impeller and the optimization impeller.

Figure 7(c) and Figure 7(d) show that the velocity distributions at 50\% span of the impeller for both models are different obviously. The velocity distribution for the original model is extremely uneven. Due to the large impeller outlet angle, the expansion ratio of impeller passage is too large, which results in severe flow separation near the exit of the suction surface. While for the optimization model, the expansion ratio of impeller passage is moderate and the flow separation near the exit of the suction surface decreases clearly, which indicates that the optimization impeller could take a better control of the flow.

Table 5. Performance comparison between the original impeller and the optimized impeller.

\begin{tabular}{cccc}
\hline Impeller & $P_{\text {tot }} / \mathrm{Pa}$ & $N_{s} / \mathrm{kW}$ & $\eta_{\text {tot }} / \%$ \\
\hline Original & 1458 & 6.3 & 0.898 \\
Optimized & 1551 & 6.4 & 0.939 \\
\hline
\end{tabular}

Table 6. Performance comparison between the original fan and the optimized fan.

\begin{tabular}{cccc}
\hline Fan & $P_{\text {tot }} / \mathrm{Pa}$ & $N_{s} / \mathrm{kW}$ & $\eta_{\text {tot }} / \%$ \\
\hline Original & 1328 & 6.1 & 0.840 \\
Optimized & 1404 & 6.2 & 0.875 \\
\hline
\end{tabular}

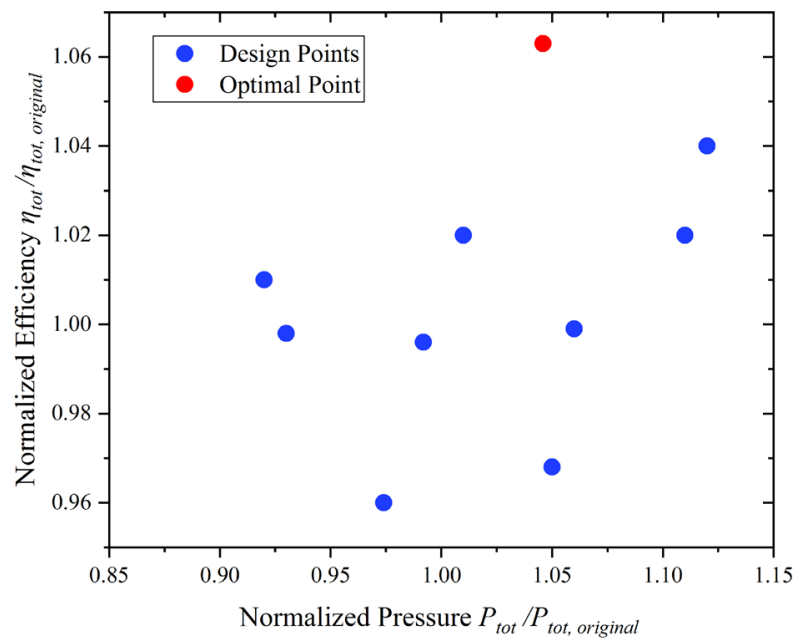

Figure 5. Distribution of the normalized pressure and the efficiency in the optimization. 


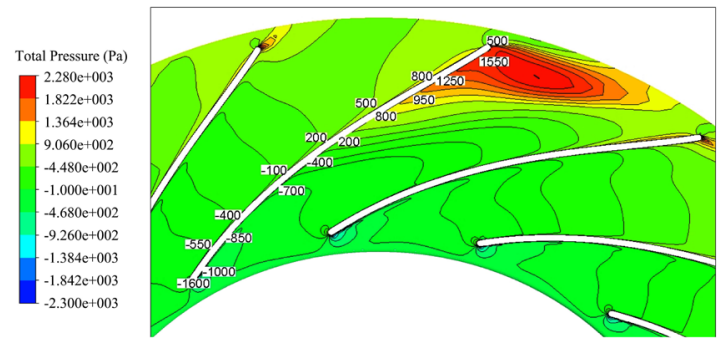

(a) original model

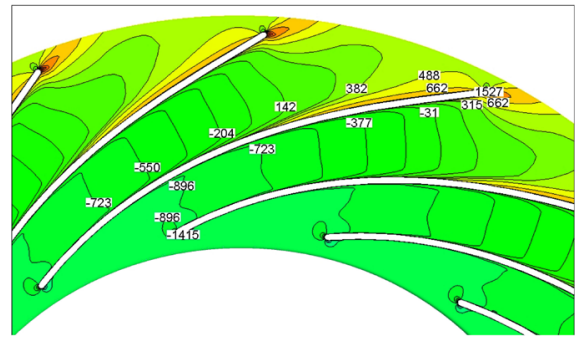

(b) optimization model

Figure 6. Total pressure distribution at $50 \%$ span of the impeller.

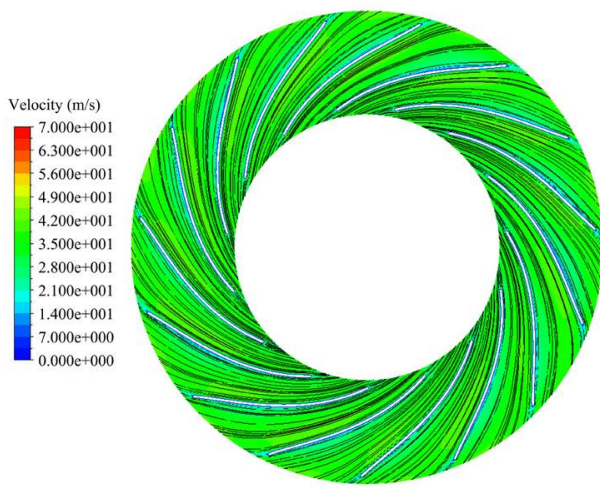

(a) $10 \%$ span, original model

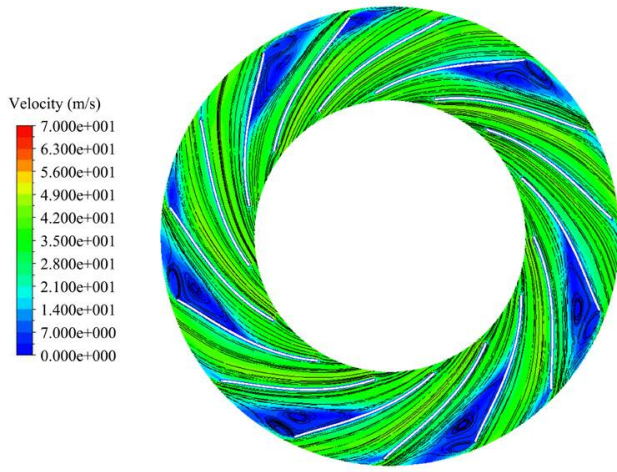

(c) $50 \%$ span, original model

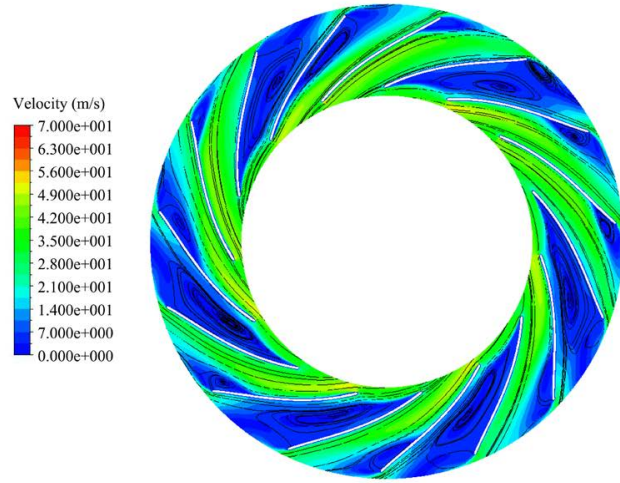

(e) $90 \%$ span, original model

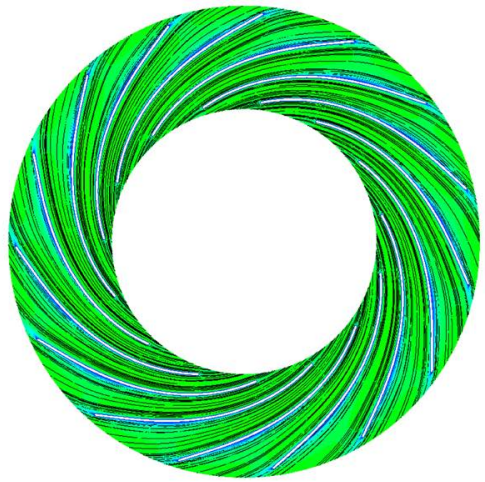

(b) $10 \%$ span, optimization model

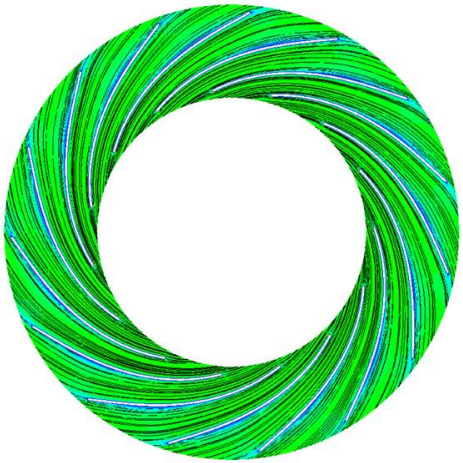

(d) $50 \%$ span, optimization model

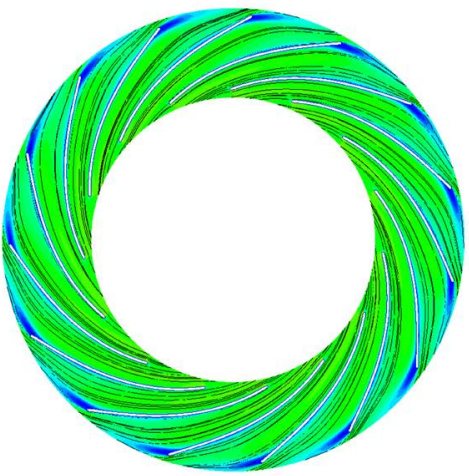

(f) $90 \%$ span, optimization model

Figure 7. Streamlines and relative velocity distributions at $10 \%, 50 \%$ and $90 \%$ span of the impeller. 
As Figure 7(e) shows, the flow separation occupies almost the entire passage near the shroud of the impeller due to the sudden expansion of the cross-section when air enters the impeller from the collector. In addition, the improper expansion ratio of impeller passage worsens the flow separation and produces large separation losses. In contrast, the flow separation almost disappears for the optimization model as Figure 7(f) shows, which indicates that the expansion ratio of impeller passage decreases properly and matches the curved shroud better. Therefore, the flow inside the impeller is greatly improved and the pressure loss is reduced significantly.

\subsection{Analysis of the Fan Internal Flow Condition}

Figure 8 shows the vortex core distribution inside the fan. The internal vortex intensity of the original fan is $1163.9 \mathrm{~s}^{-1}$, which is reduced to $946.2 \mathrm{~s}^{-1}$ after optimization. For the optimization model, the vortices are suppressed effectively, which would improve the work capacity of the impeller and the aerodynamic performance of the fan.

Figure 9 shows streamlines distribution on $90^{\circ}$ and $270^{\circ}$ sections inside the volute. Angle orientation of the sections is shown in Figure 1. Due to the sudden expansion of the cross-section from the impeller outlet to the volute, vortices will appear inside the volute. Figure 9(a) presents the streamlines inside the volute on $90^{\circ}$ cross-section for the original model. It can be seen that the flow near the impeller outlet is extremely uneven and a large-scale vortex is formed in the volute. In contrast, for the optimization model, the flow near the impeller outlet is more uniform as shown in Figure 9(c). Besides, as Figure 9(b) shows, on $270^{\circ}$ cross-section, the scale of the vortex mentioned above becomes larger and a smaller vortex appears at the back of the collector, which will cause more pressure loss. In Figure 9(d), the effect of the large-scale vortex on the flow field near the impeller outlet is weakened and the core of the vortex is father away from the impeller outlet.

The velocity vector near the volute tongue is presented in Figure 10. It can be seen that the upstream air in the volute is divided into two portions near the volute tongue: one portion flows out of the volute and another portion returns to the volute. The latter will cause the stack of the low energy fluid, which further decreases the effective cross-section near the volute tongue and influences the fan noise. Figure 10(a) and Figure 10(b) reveal that the optimization model reduces the low-energy fluid region nearby the tongue at $90 \%$ span of the impeller. Figure 10(c) and Figure 10(d) show that, at 50\% span of the impeller nearby the tongue, the low-energy fluid region is farther away from the tongue after optimization and the impeller outlet velocity of the optimization model is more uniform than that of the original model. Because of that, the effective cross-section near the volute tongue increases, which could improve the flow in the volute. At 10\% span of the impeller as shown in Figure 10(e) and Figure 10 (f), the low-energy fluid region is also smaller and farther away from the tongue after optimization. In summary, the flow field nearby the volute tongue is 
more even after optimization, which could reduce the pressure loss and the noise.

\section{Conclusions}

The optimization procedure based on Response Surface Methodology (RSM) is conducted on a centrifugal fan. The blade inlet angle $\beta_{1 A}$ and the blade outlet angle $\beta_{2 A}$ of the centrifugal impeller were taken as the optimization factors, and some improvements were obtained. The main results of this work can be concluded as follows:

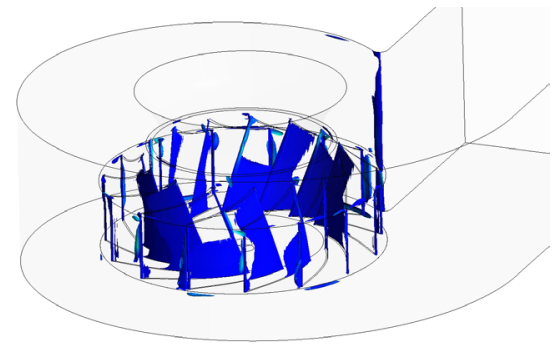

(a) original model

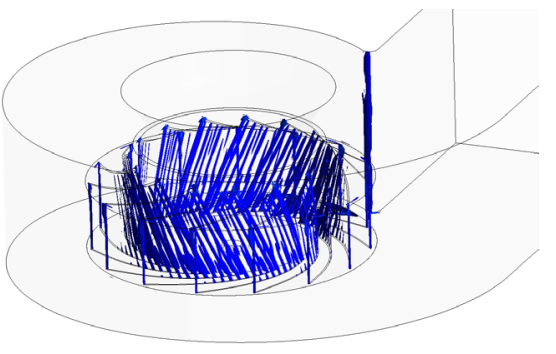

(b) optimization model

Figure 8. The distribution of the vortex core inside the fan.

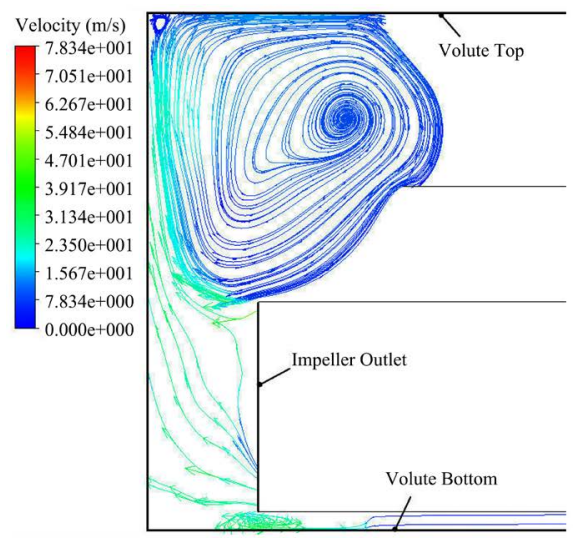

(a) $90^{\circ}$ cross-section, original model

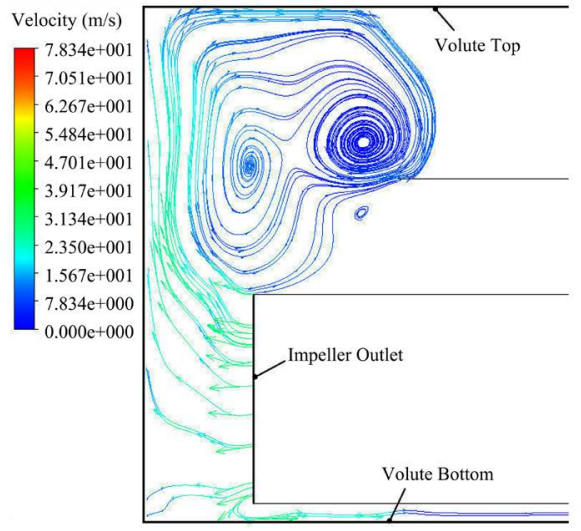

(c) $90^{\circ}$ cross-section, optimization model

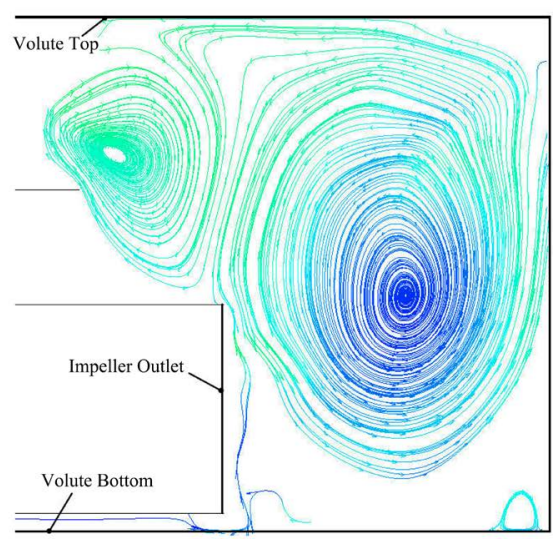

(b) $270^{\circ}$ cross-section, original model

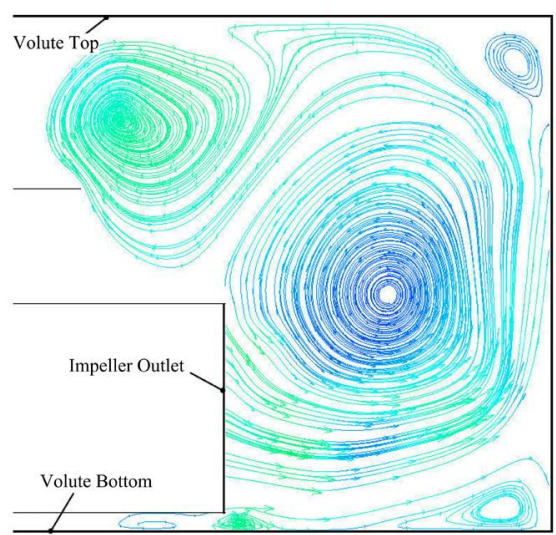

(d) $270^{\circ}$ cross-section, optimization model

Figure 9. Streamline distribution on different cross-sections. 

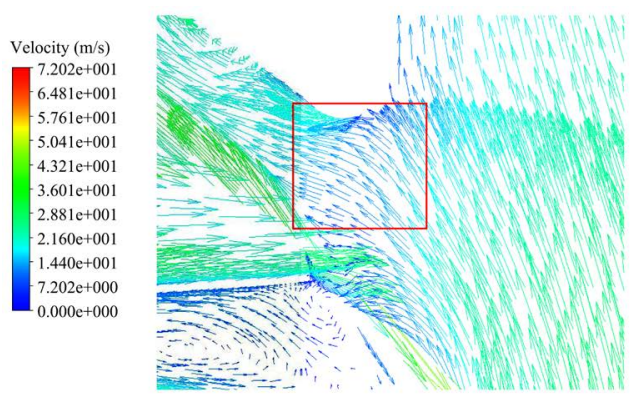

(a) $90 \%$ span, original model

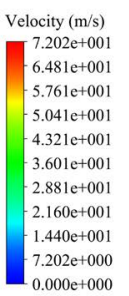

$.000 \mathrm{e}+000$

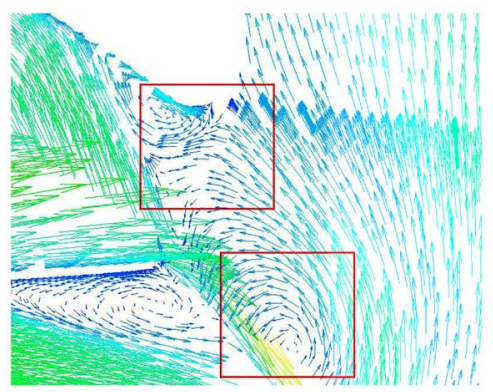

(c) $50 \%$ span, original model

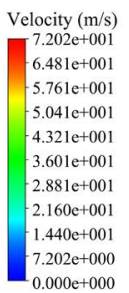

$000 \mathrm{e}+000$

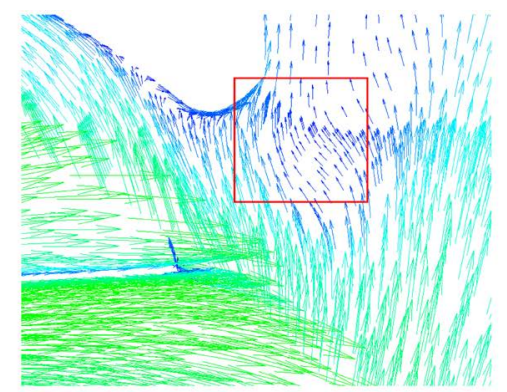

(e) $10 \%$ span, original model

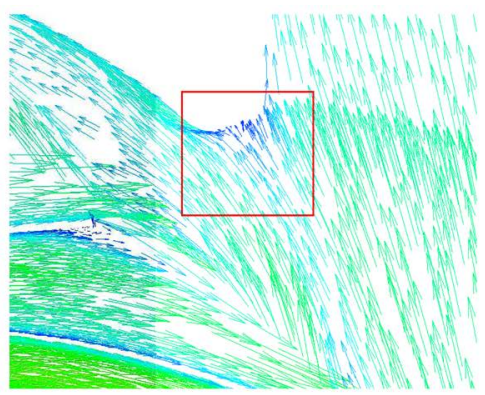

(b) $90 \%$ span, optimization model

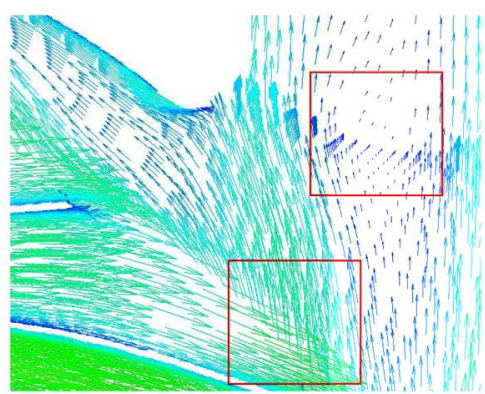

(d) $50 \%$ span, optimization model

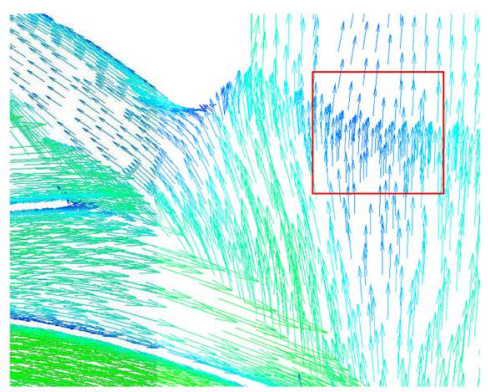

(f) $10 \%$ span, optimization model

Figure 10. The velocity vector nearby the volute tongue.

1) In the sensitivity analysis, the blade outlet angle $\beta_{2 A}$ is found to be more sensitive to the total pressure difference and the shaft power; while the blade inlet angle $\beta_{1 A}$ is more sensitive to the total-pressure efficiency. The two key parameters have great impacts on the aerodynamic performance of the centrifugal impeller and the fan.

2) The flow separation is severe near the shroud of the impeller outlet and the exit of the suction surface. Through the optimization, the reduced expansion ratio of impeller passage as well as the impact of the flow forces on the blade suppressed the local flow separation significantly.

3) The large scale vortices existing in the regions between the impeller shroud and the volute are suppressed. The flow field stability around the volute tongue is also improved, and the local fields with low-energy fluid are reduced.

4) The flow field characteristics obtained in this paper could be useful in the later design or optimization procedure of the centrifugal fan. Besides, the method which considers the blade inlet angle $\beta_{1 A}$ and the blade outlet angle $\beta_{2 A}$ of 
the centrifugal impeller as optimization parameters has improved the total pressure difference and the total-pressure efficiency by $5.7 \%$ and $4.2 \%$ respectively.

\section{Acknowledgements}

This work was financially supported by the National Key R\&D Program of China (2018YFB0606101) and the Natural Science Foundation of China (51876158 and 51776145).

\section{Conflicts of Interest}

The authors declare no conflicts of interest regarding the publication of this paper.

\section{References}

[1] Li, Y.Q. (1981) Fan. China Machine Press, Beijing.

[2] Amladimanesh, A., Ajam, H. and Nezhad, H. (2015) Numerical Study of Blade Number Effect on the Performance of 3D FC Centrifugal Fan. International Journal of Mechatronics, Electrical and Computer Technology, 5, 2109-2119.

[3] Shibata, T., Yagi, M., Nishida, H., Kobayashi, H. and Tanaka, M. (2011) Performance Improvement of a Centrifugal Compressor Stage by Increasing Degree of Reaction and Optimizing Blade Loading of a Shrouded 3D Impeller. Journal of Turbomachinery, 133, 1305-1315. https://doi.org/10.1115/1.4000565

[4] Zangeneh, M., Amarel, N., Daneshkhah, K. and Krain, H. (2011) Optimization of 6.2:1 Pressure Ratio Centrifugal Compressor Impeller by 3D Inverse Design. Proceedings of ASME Turbo Expo 2011, Vancouver, 6-10 June 2011, 2167-2177. https://doi.org/10.1115/GT2011-46505

[5] Kim, J.H., Choi, J.H. and Kim, K.Y. (2010) Surrogate Modeling for Optimization of a Centrifugal Compressor Impeller. International Journal of Fluid Machinery and Systems, 3, 29-38. https://doi.org/10.5293/IJFMS.2010.3.1.029

[6] Chen, X. and Agarwal, R.K. (2013) Shape Optimization of Airfoils in Transonic Flow Using a Multi-Objective Genetic Algorithm. Journal of Aerospace Engineering, 228, 1654-1667.

[7] Torshizi, S.M., Benisi, A.H. and Durali, M. (2017) Multilevel Optimization of the Splitter Blade Profile in the Impeller of a Centrifugal Compressor. Scientia Iranica, 24, 707-714. https://doi.org/10.24200/sci.2017.4055

[8] Xia, C.C., Jiang, T.T. and Chen, W.F. (2016) Particle Swarm Optimization of Aerodynamic Shapes with Nonuniform Shape Parameter-Based Radial Basis Function. Journal of Aerospace Engineering, 30, Article ID: 04016089.

[9] Zhao,Y.S., Liu, B., Xiao, C.M. and Xiao, F.L. (2016) Optimization of Tandem Blade Based on Improved Particle Swarm Algorithm. ASME Turbo Expo 2016: Turbomachinery Technical Conference and Exposition, Seoul, 13-17 June 2016, V02CT45A015.

[10] Andrés-Pérez, E., González-Juárez, D., Martin-Burgos, M.J., Carro-Calvo, L. and Salcedo-Sanz, S. (2017) Influence of the Number and Location of Design Parameters in the Aerodynamic Shape Optimization of a Transonic Aerofoil and a Wing through Evolutionary Algorithms and Support Vector Machines. Engineering $O p$ timization, 49, 181-198. https://doi.org/10.1080/0305215X.2016.1165568

[11] Ghorbanian, K. and Gholamrezaei, M. (2009) An artificial Neural Network Ap- 
proach to Compressor Performance Prediction. Applied Energy, 86, 1210-1221. https://doi.org/10.1016/j.apenergy.2008.06.006

[12] Chu, F., Wang, F., Wang, X. and Zhang, S. (2014) A Hybrid Artificial Neural Network-Mechanistic Model for Centrifugal Compressor. Neural Computing and Applications, 24, 1259-1268. https://doi.org/10.1007/s00521-013-1347-5

[13] Sevant, N.E., Bloor, M.I. and Wilson, M.J. (2000) Aerodynamic Design of a Flying Wing Using Response Surface Methodology. Journal of Aircraft, 37, 562-569. https://doi.org/10.2514/2.2665

[14] Guo, S., Duan, F., Tang, H., Lim, S.C. and Yip, M.S. (2014) Multi-Objective Optimization for Centrifugal Compressor of Mini Turbojet Engine. Aerospace Science and Technology, 39, 414-425. https://doi.org/10.1016/j.ast.2014.04.014

[15] Benim, A., Diederich, M. and Pfeiffelmann, B. (2018) Aerodynamic Optimization of Airfoil Profiles for Small Horizontal Axis Wind Turbines. Computation, 6, 34. https://doi.org/10.3390/computation6020034

[16] Jang, C.M. and Kim, K.Y. (2005) Optimization of a Stator Blade Using Response Surface Method in a Single-Stage Transonic Axial Compressor. Journal of Power and Energy, 219, 595-603. https://doi.org/10.1243/095765005X31298

[17] Tang, X., Luo, J. and Liu, F. (2017) Aerodynamic Shape Optimization of a Transonic Fan by an Adjoint-Response Surface Method. Aerospace Science and Technology, 68, 26-36. https://doi.org/10.1016/j.ast.2017.05.005

[18] Wang, K.B., Ai, X., Zhang, R.Z. and Li, J.Y. (2018) Optimization of a Centrifugal Impeller with the Constraint on Efficiency at the Stall Point. Open Journal of Fluid Dynamics, 8, 15-29. https://doi.org/10.4236/ojfd.2018.81002 